\title{
Time Series Analysis for Shortened Labor Mean Interval of Dairy Cattle with the Data of BCS, RFS, Weight, Amount of Milk and Outlook
}

\author{
Kohei Arai, Osamu Fukuda, \\ Hiroshi Okumura \\ Graduate School of Science and \\ Engineering \\ Saga University \\ Saga City, Japan
}

\author{
Kenji Endo \\ Morinaga Dairy Service Co. Ltd. \\ 1-159 Toyoharaotsu, Nasugun \\ Nasumachi, \\ Tochigi 329-3224, Japan
}

\author{
Kenichi Yamashita \\ The National Institute of Advanced \\ Industrial Science and Technology \\ (AIST), 807-1 Shuku-machi, Tosu \\ Saga 841-0052, Japan
}

\begin{abstract}
Time series analysis for shortened labor mean interval of dairy cattle with the data of BCS (Body Condition Mass), RFS (Rumen Fill Score), Weight, Amount of Milk and Outlook is conducted. Method for shortened the labor mean internal of Japanese dairy cattle based on time-series analysis with the data of visual index of BCS, RFS, Weight, Amount of Milk and Outlook is proposed. In order to shortened the labor mean interval of dairy cattle is the purpose of this research. Through the experiments with 17 Japanese dairy cattle of the 17 Japanese anestrus Holstein dairy cattle, it is found that the combination of weight, BCS and amount of milk is a good indicator for identification of productive cattle. Therefore, the cattle which need hormone treatments can be identified.
\end{abstract}

Keywords-Body Condition Score (BCS); Rumen Fill Score (RFS); dairy cattle; time-series analysis; cattle productivity

\section{INTRODUCTION}

The labor mean interval is defined as the period between a delivery and the next delivery. The labor mean of dairy cattle is getting longer and longer in the world wide basis. This implies that the total number of dairy cattle is getting down. Therefore, it is very serious problem so that there is strong demand to shortened the labor mean interval.

The labor mean interval of Japanese dairy cattle is approximately 410 days. This means that most of Japanese dairy cattle delivers calf about 410 days after the previous delivery typically. Country's improved growth target days is 380 days. Therefore, the labor mean interval of Japanese dairy cattle has to be shortened by 30 days (410 to 380 days of labor mean interval would be a goal).

There are so many trials for identify the labor mean interval. Among the many factors of cattle productivity influence, the most influential one is the Body Condition Score: BCS, which is defined as "an effective management tool to estimate the energy reserves of a cow" [1]-[3] and most widely used for herd management. There are many identified system for measuring BCS, which varies according to different countries [1], [2]. Using BCS to evaluate cattle does not require any special equipment and can be conducted anytime during the year. Poor body condition is associated with reduced income per cow, increased postpartum interval, increased dystocia, and lower weaning weight. The most common and widely used (USA and Japan) BCS scale ranges from 1 to 5 with 0.25 increments [3]. Though BCS measured subjectively and its reliability is questioned, it is also evident that BCS have relationship with many other factors of bovine, such as postpartum interval, parity, etc. [3]-[6]. The authors have proposed the method for estrus cycle estimation with three influential factors (BCS, postpartum interval, and parity) for understanding the presence and absence of estrous cycle using a new unique Bayesian Network Model: BNM [7]. It, however, is not possible to consider a relation among the influencing factors.

Although ultrasound diagnostic instruments allow identifying pregnancy (major follicle in ovary) relatively easily, the instruments are not so cheap and not so easy to use for dairy cattle farmers. Therefore, there are strong demands for identification of pregnancy in easy way without any expensive instrument. BCS, RFS, weight, amount of milk and outlook are easy to measure and comprehensive.

In this paper, regressive analysis-based method for estrus cycle estimation is proposed here in this paper in order to consider a relation among the influencing factors. Experiments are conducted with 17 different Japanese Holstein cows observing with their BCS (2.0 to 3.25), hormonal treatments and parity numbers in order to discover the ideal timing for artificial insemination to make them pregnant. These data are acquired from the dairymen in Nasu-machi, Tochigi Prefecture. It is also important to mention that, all these 17 samples found anestrus in their farm.

The aim of the research work is to find out estimation equation of estrous cycle of bovine using regressive analysis for Japanese dairy industries. It is clear from National Livestock Breeding Center: NLBC, Japan that, the overall conception rate of live beef and dairy cattle is decreasing in last 20 years in Japan [8]. Moreover, the findings of relations among influencing factors of the measured BCS, hormone treatments, parity number, and so on are other objectives for improving cattle productivity and herd management. Moreover, using regressive analysis would assist the farm 
management to find out the presence of estrous cycle more objectively and in an accurate way. Meanwhile, method for productive cattle finding with estrus cycle estimated with BCS and parity number and hormone treatments based on a regressive Analysis is proposed already [9].

In this paper, the following influencing factors for estimation of estrus cycle as well as the labor mean interval, BCS, RFS, weight, amount of milk, and outlook are focused. Detection of major follicles and measurement of blood flow by ultrasonic diagnostic images in the ovaries are effective for estrus detection. It, however, does cost for ultrasonic imager. Meanwhile, aforementioned five factors can be measured relatively easy and do not need expensive instruments at all. Therefore, the five factors are focused in this paper. If productive dairy cattle can be identified, breeding of such cattle. Also, if detection of estrus can be done and if pregnancy cannot be confirmed, then appropriate hormone treatments can be done. This is a basic approach for shortened the labor mean interval.

The following section describes research background followed by preliminary results from the relation between the labor interval and the aforementioned influencing factors. Then, the most influencing factor is determined through time series data analysis followed by conclusion with some discussions.

\section{RESEARCH BACKGROUND}

\section{A. Body Condition Score}

The research reveals to include BCS while considering the estrous cycle identification. BCS is the most significant influential factors in bovine productivity. An organized process for determining BCS was created at the University of Pennsylvania to help achieve consistency and repeatability in BCS. This system finds its accuracy toward the mid-range scores (2.50 to 4.00), which includes most cattle in this investigation. This mid-range is the most critical for making farm management decisions and most influential for the farm nutritionist. BCS outside this range indicate significant problems and varies significantly with respect to each individual inspector/observer. This research considering $\mathrm{BCS}_{4.0}$ methods (quarter-point increase) in 17 individual cattle of Morinaga Dairy Service: MDS Co. Ltd. Japan and the following tables describe the meaning of BCS scale. The $\mathrm{BCS}_{4.0}$ method ( 0.25 increase) have good repeatability across and within observers including simplified body scoring as well as have higher value as a diagnostic test.

The BCS process represents the observer's view into the certain anatomical sites for each cow's pelvic, loin areas, pin and hook bones, etc. Table I briefly elaborates the observing BCS of 17 individual cows from a farm of Iwate Prefecture, Japan under MDS cooperation.
TABLE I. BCS AND IT'S GENERAL MEANING FOR 17 SAMPLE COWS

\begin{tabular}{|l|l|}
\hline BCS & Meaning (in general) \\
\hline 2.25 & No fat pads on pin and hook bones- angular shape \\
\hline 2.5 & Palpable fat pads on pin and hook bones- angular shape \\
\hline 2.75 & $\begin{array}{l}\text { Pin bones- round shape and hook bones- angular shape with } \\
\text { less fat pads }\end{array}$ \\
\hline 3.0 & Fat pads on pin and hook bones- round shape \\
\hline 3.25 & Visible fat pads on pin and hook bones- round shape \\
\hline
\end{tabular}

The BCS data is acquired on the time mainly be the fresh time after delivery (30 to 60 days) and the milking period until conception.

\section{B. Rumen Fill Score}

RFS is associated with feed intake. Also, it is known that RFS is related to blood parameters (Condition). RFS can be measured visually easily.

It is confirmed that RFS does not change in pregnant cows. For non-pregnant cows, RFS decreases gradually as the calving day approached. After calving, non-pregnant cows showed lower energy status compared with pregnant cows, and some non-pregnant cows showed anovulation and cessation of estrous cycle.

RFS is evaluated with the swelling of the apparent lefthand part (left side flank with the first stomach) to the last. It will be an indicator of satiety. In addition, the cow that is always full of satiety becomes an image like a car with a large volume of rumen and so-called engine displacement (large input and output). Therefore, aim for the highest score of 5 in the dry milk (prenatal) period is attempted. The uterus also gets bigger due to the development of the fetus, and the bait eating falls down, but it is vital to make it eat better. RFS data acquisition time is the same time as the above acquisition of BCS.

\section{Hormone Treatments}

Hormone treatments can be divided into two categories, CIDR (Vaginal indwelling type luteinizing hormone preparation, and Prepare estrus), and PG (Prostaglandin, and Uterine empyema).

Usually, CIDR is applied to the dairy cattle which has no estrus for a long time for prompt an estrus. If the CIDR does not work, then PG is applied to the cattle. PG has a function to regain corpus luteum. The corpus luteum is a structure on the ovary that produces progesteron. By injection of PG, estrus is induced by follicles growing without closing by losing corpus luteum (progesteron disappears). The purpose of using PG here triggers estrus. (Cow with corpus luteum due to uterine empyema is also used for treatment to release pus in the uterus by administration of PG, but estrous induction is the main in program insemination. 


\section{Weight}

Weight of dairy cattle can also be measured easily. Usually, weight of dairy cattle decreases after delivery and gradually recovered for preparation of the next pregnancy. For body weight measurements, A weight scale is used in this survey. Study farmers do not have a usual scale. Major measures to measure weight by measuring the prescribed chest circumference.

\section{E. Amoount of Milk}

Amount of milk is another factor for the dairy cattle. Amount of milk is highly correlated with healthy condition, bait status, productivity of the dairy cattle.

Amount of milk is defined as "Milk amount [kg] of measurement month (-1 without survey)" in this paper.

\section{F. Outlook}

Outlook is the factor which is reflected with appearance findings (1: Good taste 2: Normal 3: Danger 4: Impossible (difficult recovery) 5: Judgment pending). As a survey destination, these data are acquired as a dairy farmer in Nasucho, Nasu-gun, Tochigi Prefecture, Japan.

\section{TIME SERIES ANALYSIS}

\section{A. Features of the Time Series of Raw Data}

These 17 individual sample data of dairy cattle were collected from a dairy farm of Iwate Prefecture with the cooperation of Morinaga Dairy Service: MDS Co. Ltd., Japan. The BCS were observed in accordance with the UV method of Ferguson [3] by an experienced animal scientist of MDS. The PPI, Parity and other related information is collected from MDS. These 17 individual cattle were Japanese Holstein breed, which were found anestrus in the farm in Iwate Prefecture, Japan. The overall investigation for all these problematic dairy cow is under observation of MDS. Fig. 1 shows time series of data of the aforementioned influencing factors of the dairy cattle which has the data for more than 250 days after the previous delivery. There are 17 of the dairy cattle with the data for much longer than 250 days out of the 17 candidates of the Japanese dairy cattle.

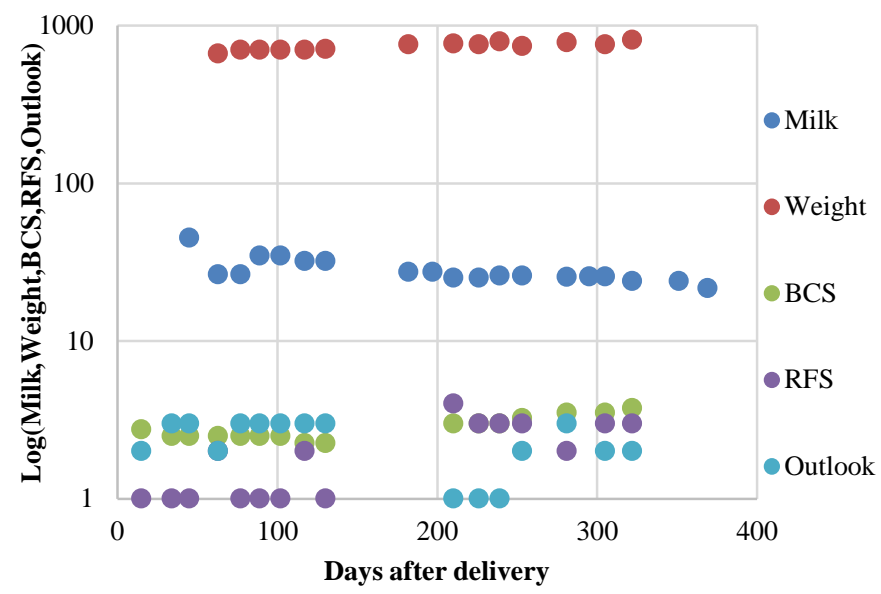

(a)

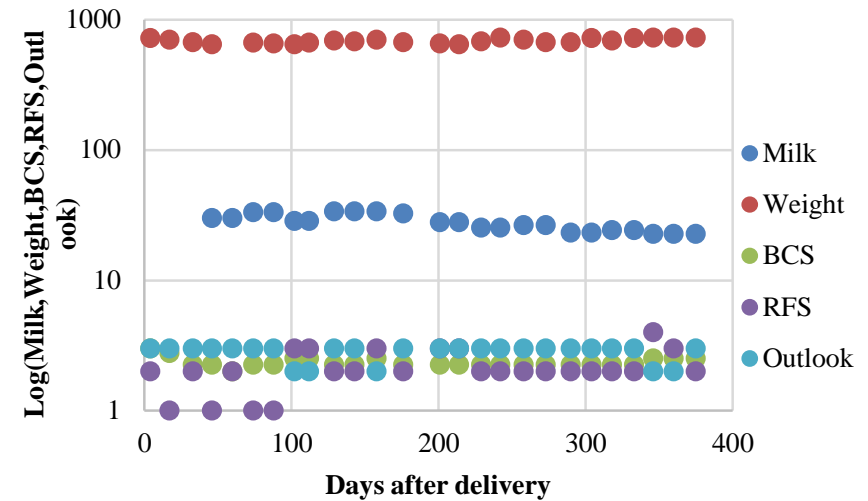

(b)

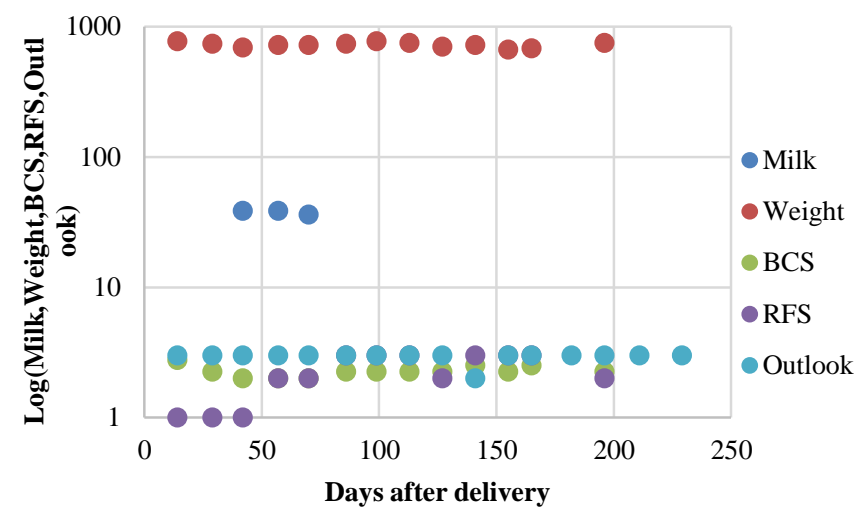

(c)

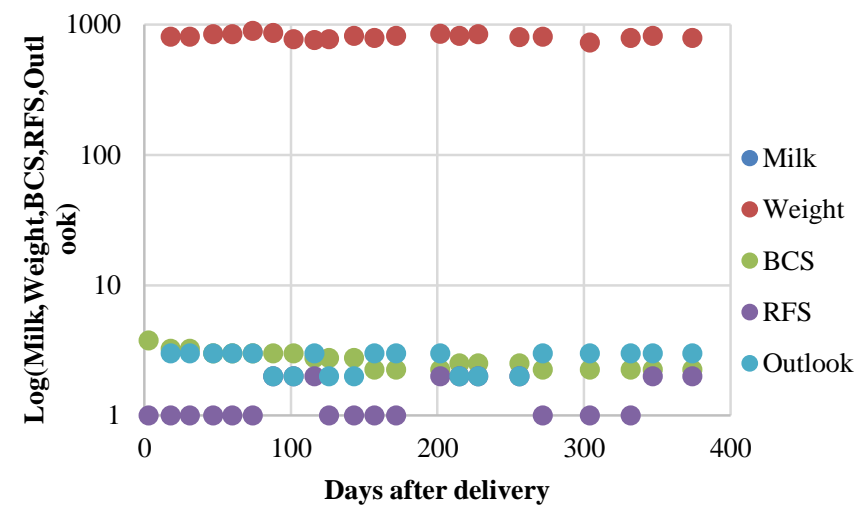

(d)

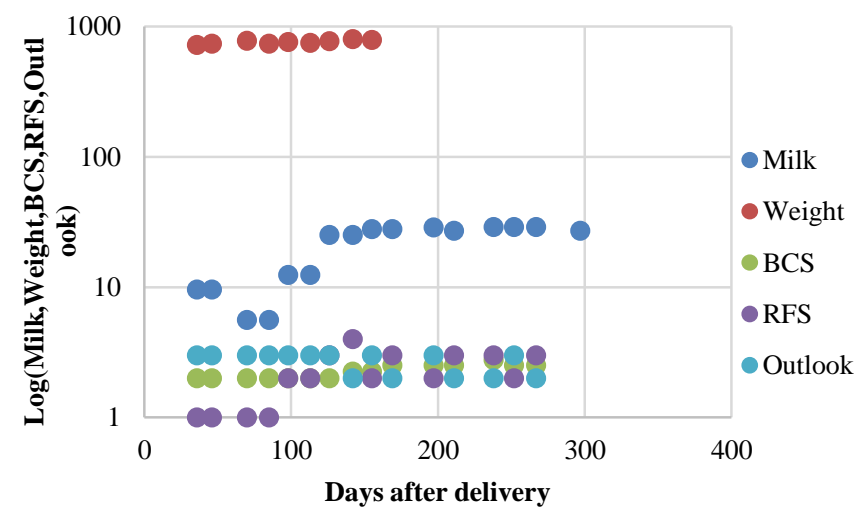

(e) 


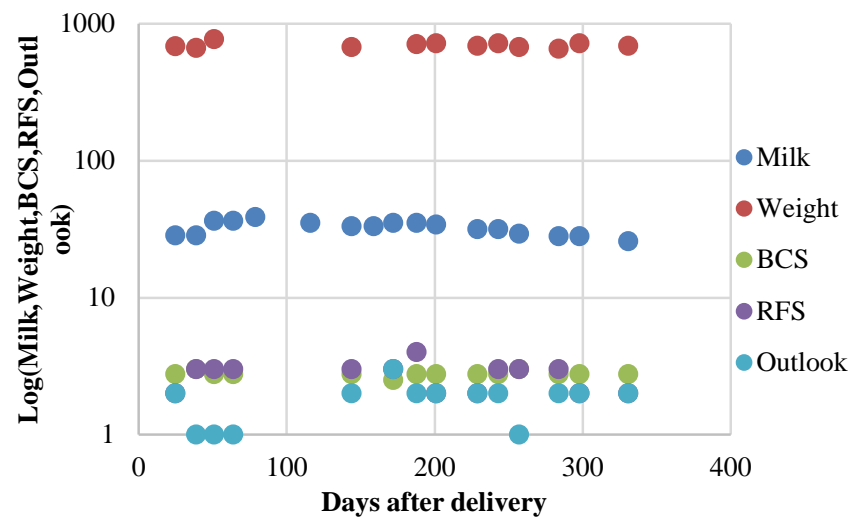

(f)

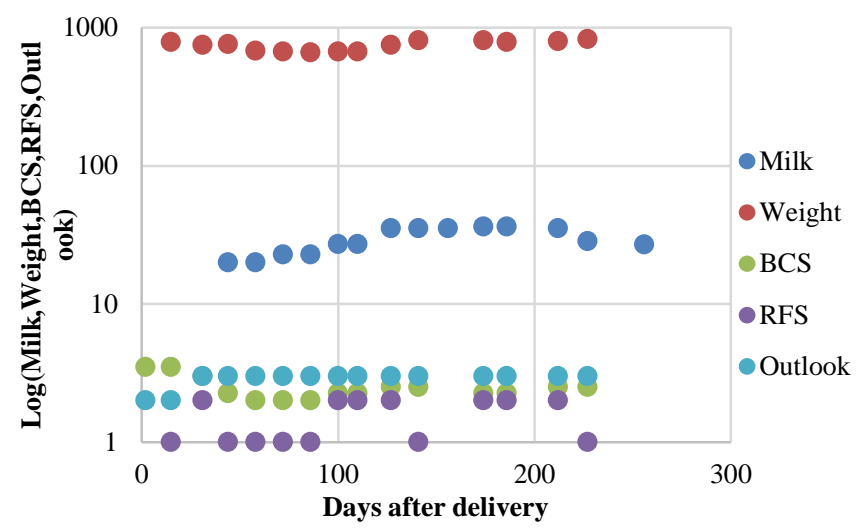

(g)

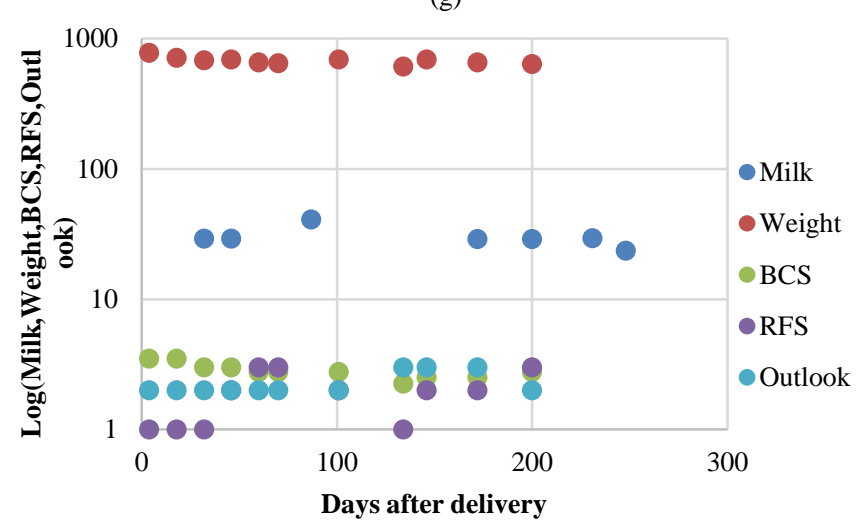

(h)

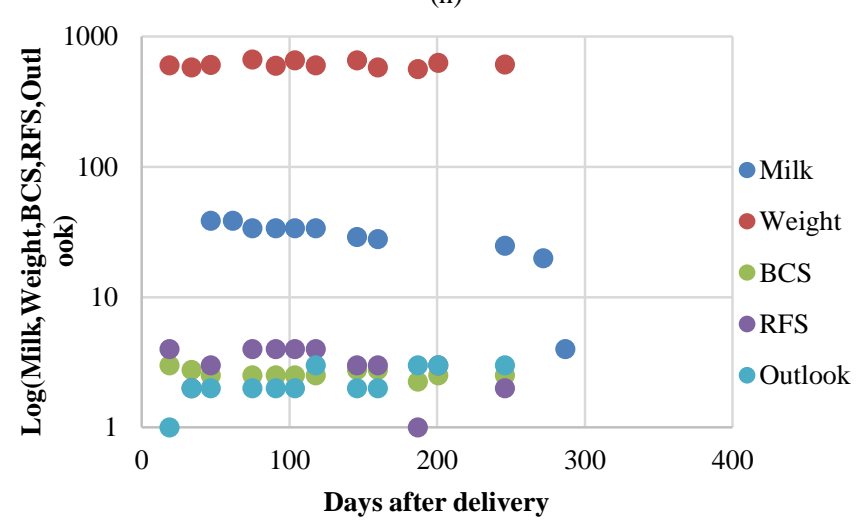

(i)

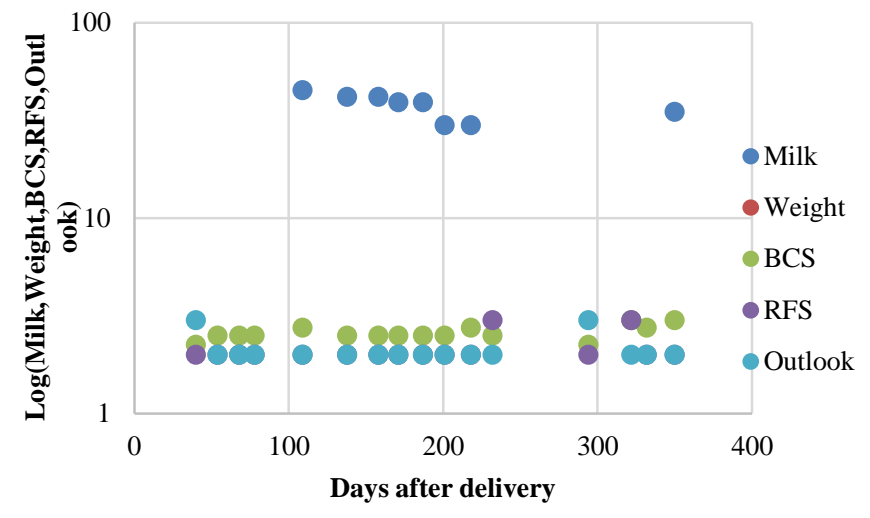

(j)

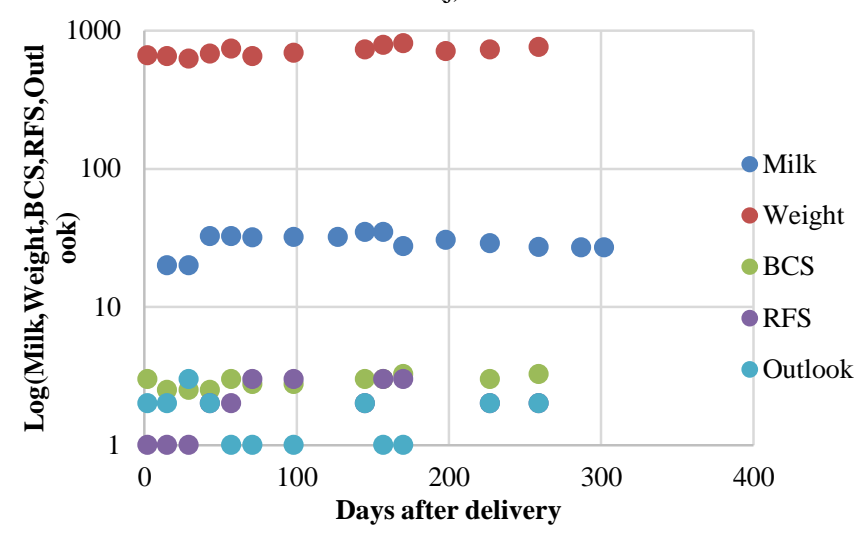

(k)

Fig. 1. Time series of data of the influencing factors.

Remarkable features of the time series of data are as follows:

1) Weight of the dairy cattle is getting down just after the delivery. Then, it is recovered gradually.

2) Amount of milk is varied up and down for some dairy cattle. It is getting down for some other dairy cattle.

3) BCS is decreased just after the delivery. Then, it is recovered gradually for some dairy cattle. There are some other dairy cattle which show almost no change.

4) RFS is relatively steady and fluctuated randomly a little bit.

5) Outlook is also relatively steady and fluctuated randomly a little bit.

\section{B. Major Results from the Time Series Analysis}

Fig. 2 shows the trends of the aforementioned influencing factors, Amount of milk, Weight, RFS, BCS, and Outlook. Overall trend of the amount of milk shows decreasing except some dairy cattle. Therefore, it cannot be an index of the recovering their readiness of pregnancy. Meanwhile, BCS shows the trend of which their BCS decreases just after their delivery and then the BCS is gradually increased except some dairy cattle. Some of the dairy cattle are not ready for pregnancy one year after the previous delivery for some reasons. Although weight, outlook, RFS of such dairy cattle shows recovering of the readiness of pregnancy, amount of 
milk of such dairy cattle is not increased Therefore, BCS is a good indicator of the readiness of pregnancy.

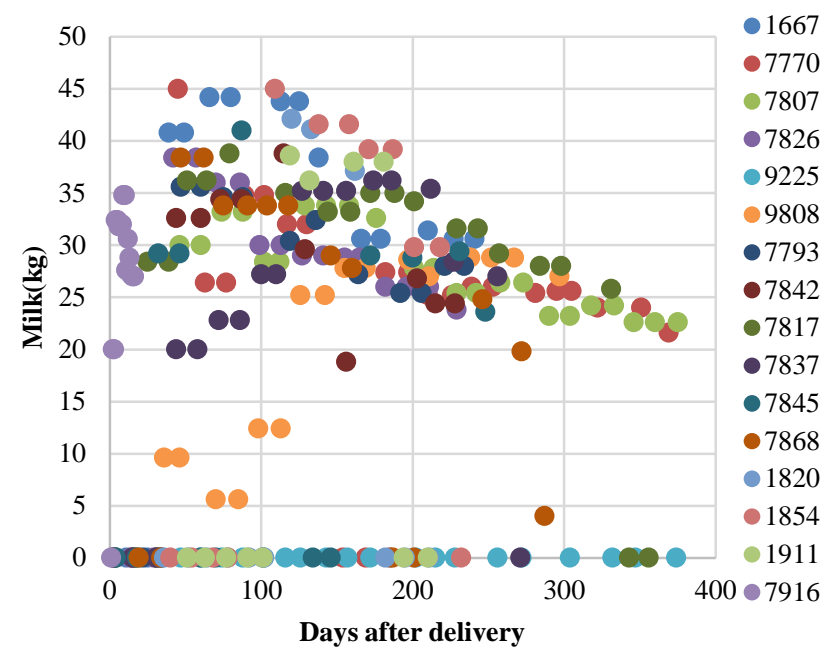

(a) Amount of Milk

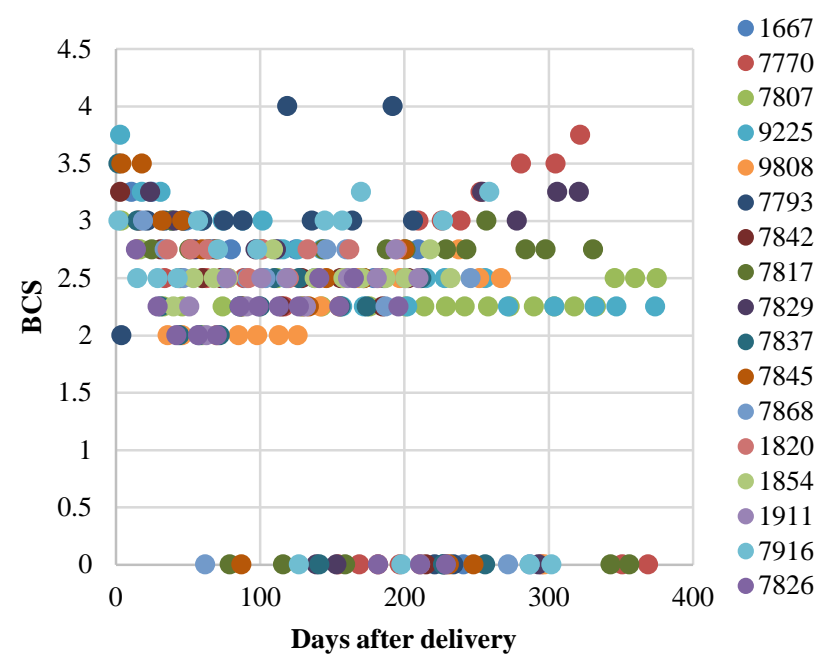

(b) BCS

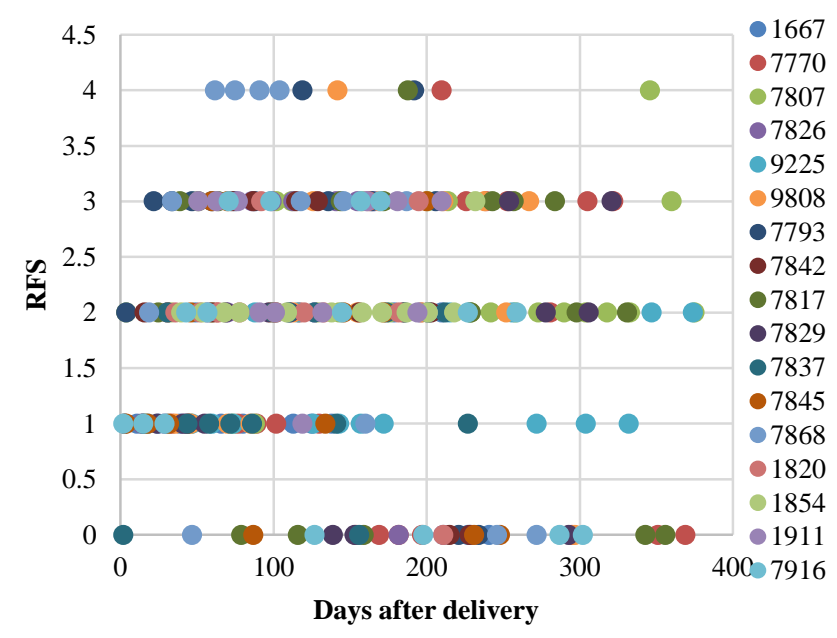

(c) RFS

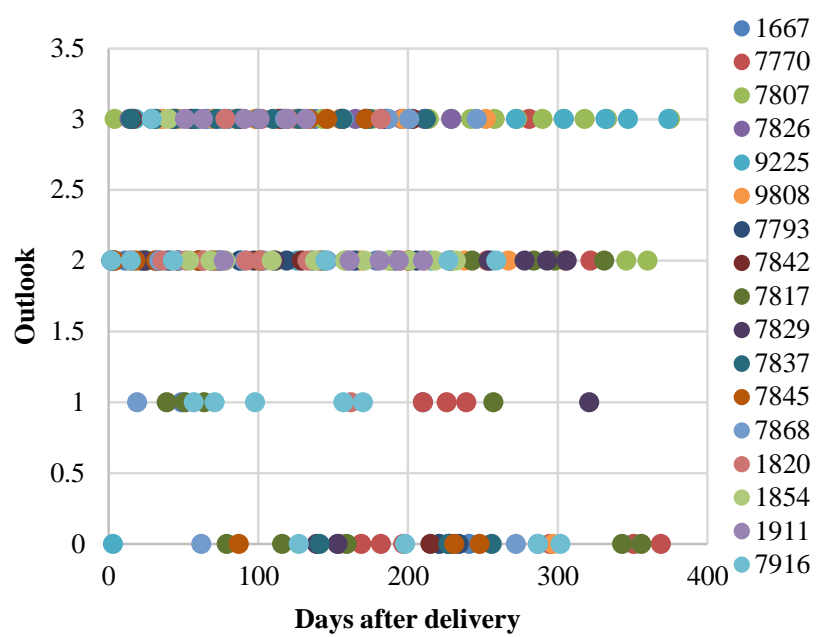

(d) Outlook

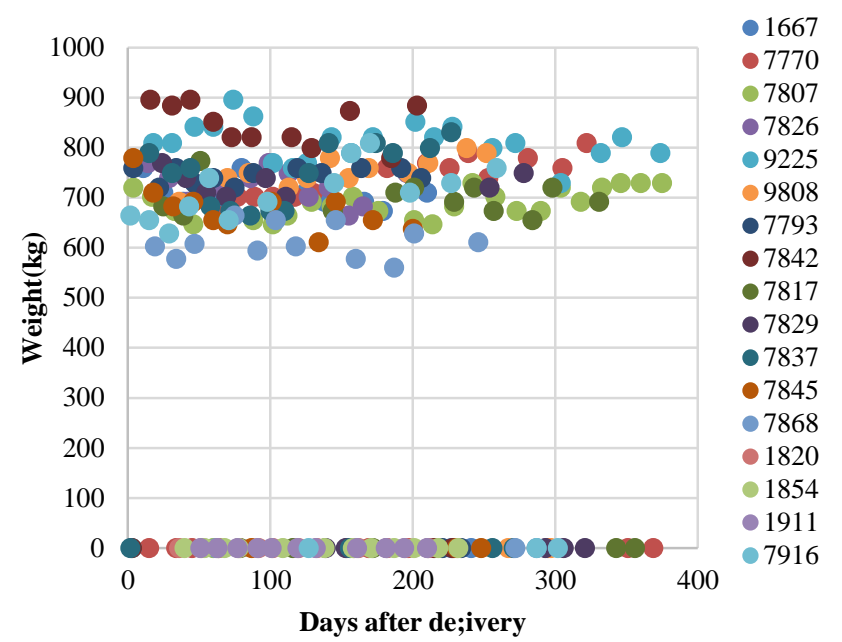

(e) Weight

Fig. 2. Trends of Amount of Milk, BCS, RFS, Outlook, and Weight of 17 of the Dairy Cattle.

On the other hand, outlook and RFS are varied up and down randomly. Therefore, both of outlook and RFS are not good indicator for their readiness of pregnancy. Weight of the dairy cattle, meanwhile, is getting down just after the delivery and gradually recovering their weight after that except some dairy cattle of which the dairy cattle are not ready for pregnancy yet nevertheless weight is recovered. Therefore, weight can be a possibility of a good indicator for their readiness of pregnancy.

\section{Extracting Sensitive Feature}

In order to enhance the feature of the time series of data, the percentage ratios $r$ of the influencing factors $\mathrm{x}$ is calculated with (1).

$r=\left(x-x^{\prime}\right)^{*} 100 / x^{\prime}$

Where $x$ ' denotes the first data $x$ at the begging of measurement Therefore, $r$ implies change rate of $x$.

Fig. 3 shows the change rate of the influencing factors, weight, BCS and amount of milk for 17 of the Japanese dairy cattle. As shown in Fig. 3, outlook and RFS are not 
appropriate factors. Therefore, these two factors are not taken into account. It is much clear that BCS is decreasing just after the delivery and then it is recovered gradually except a few dairy cattle. Also, it is found that amount of milk changes randomly during recovery stage. That is the same thing for weight of the dairy cattle.

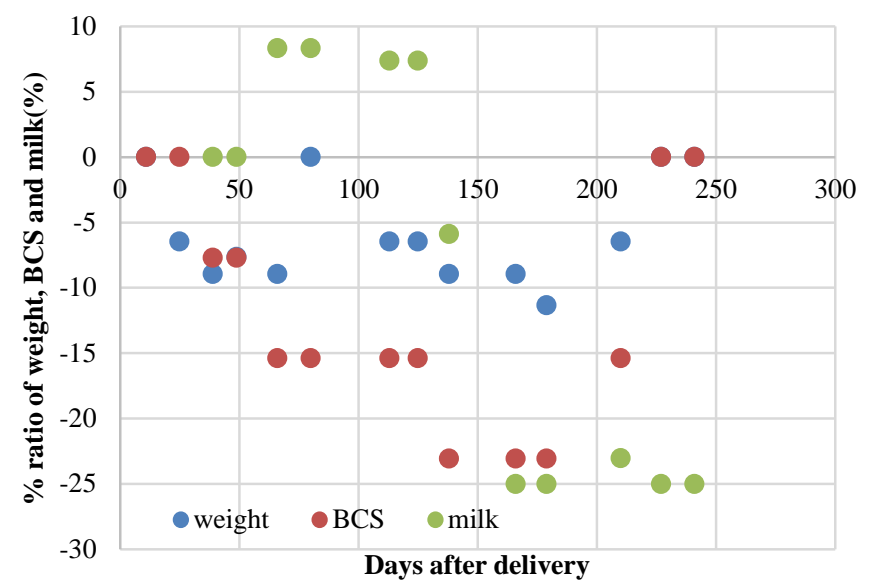

(a)

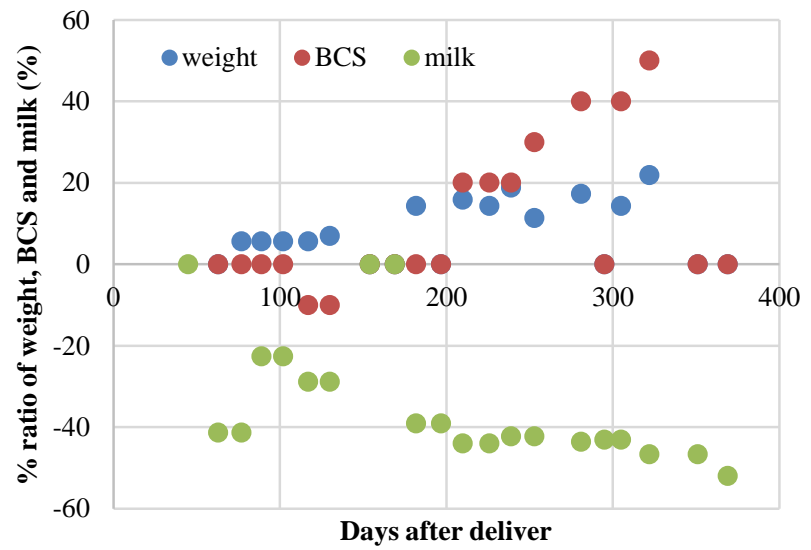

(b)

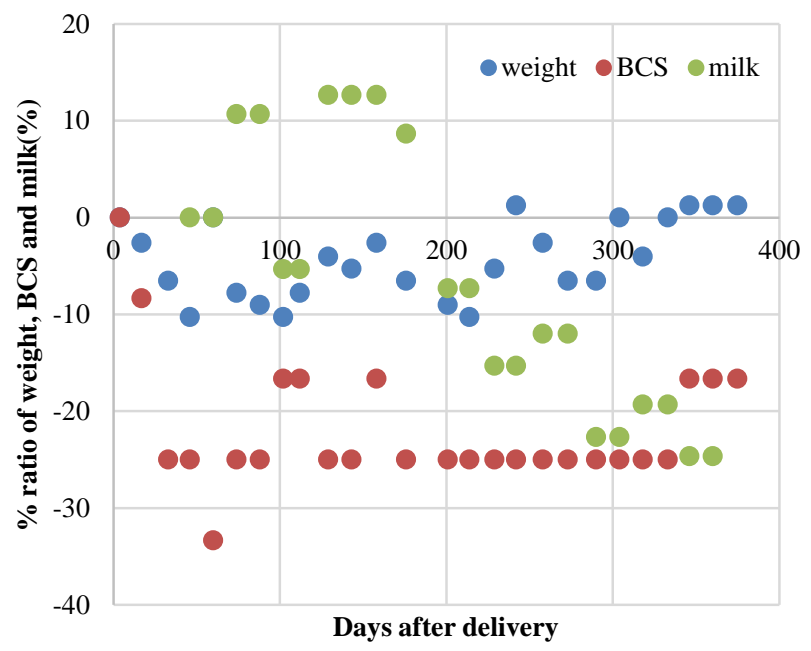

(c)

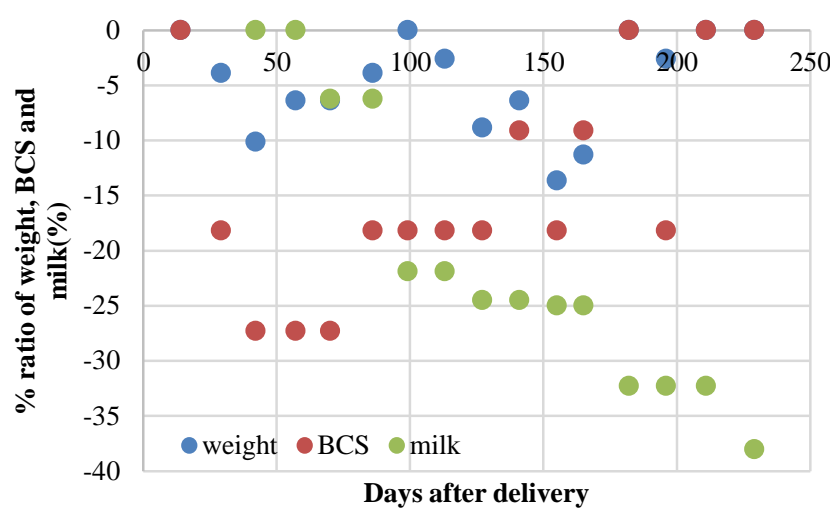

(d)

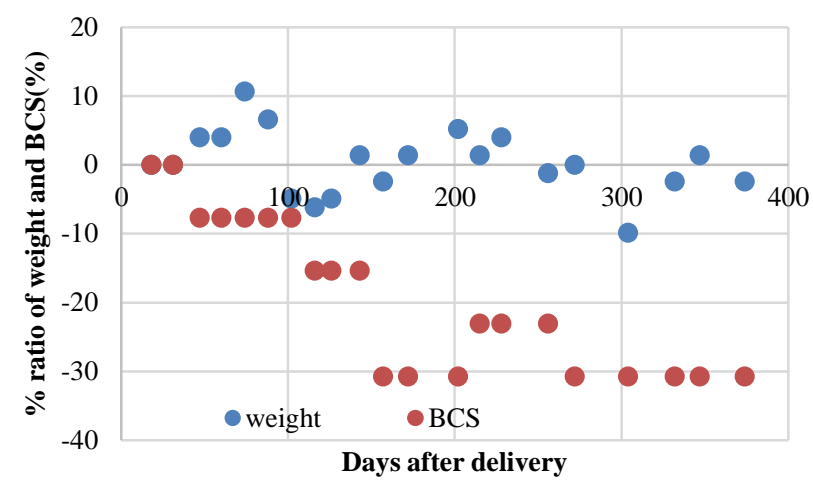

(e)

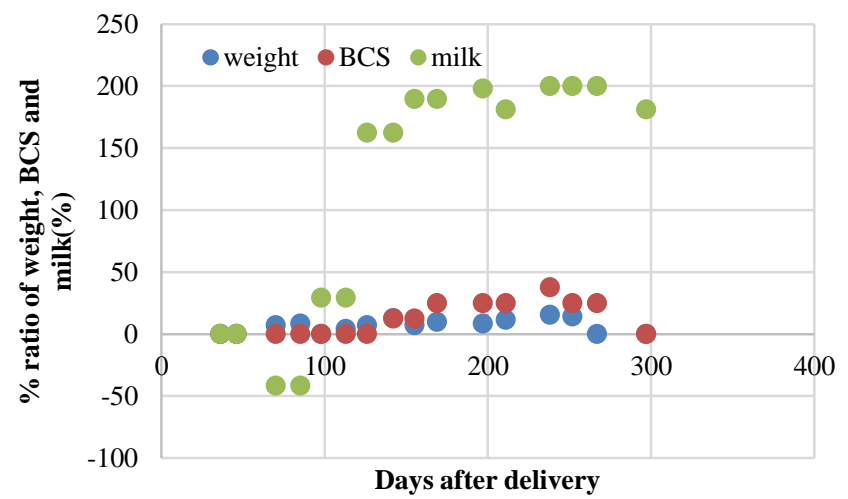

(f)

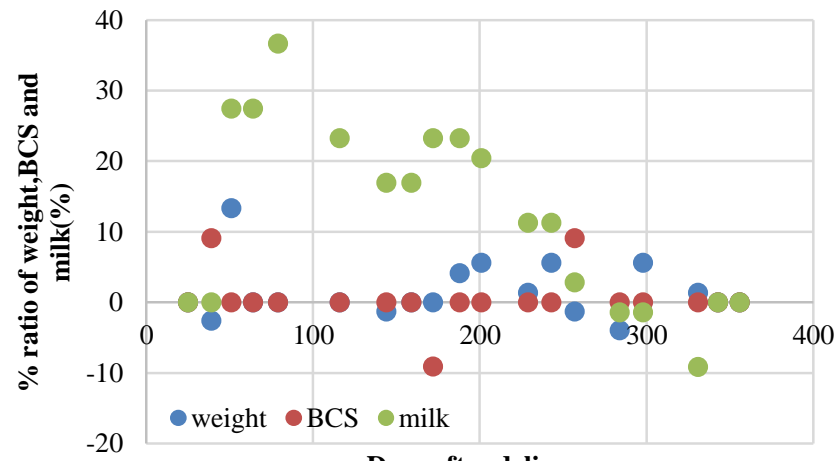

Days after delivery

(g) 


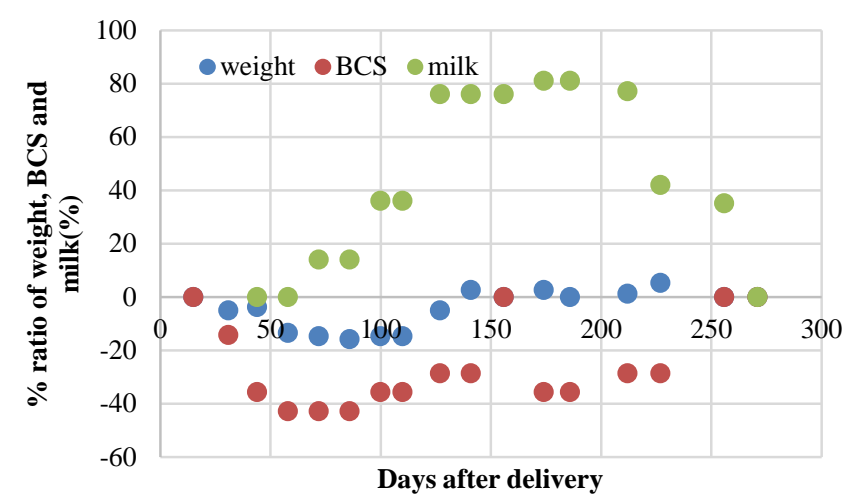

(h)

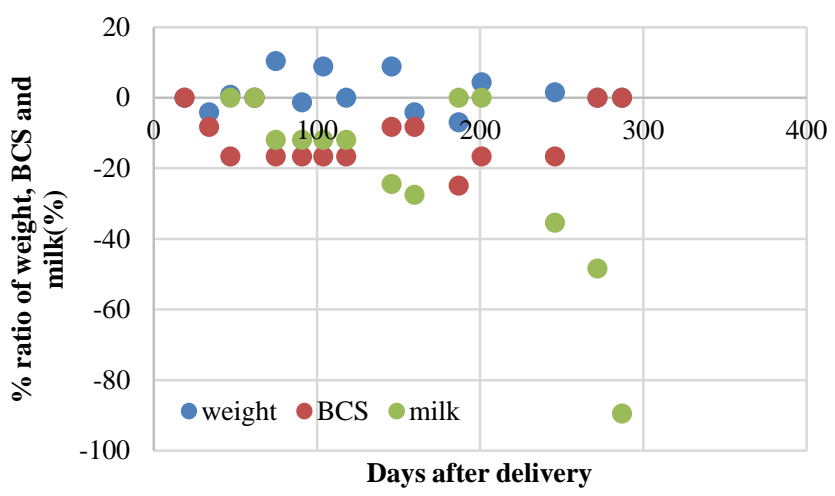

(i)

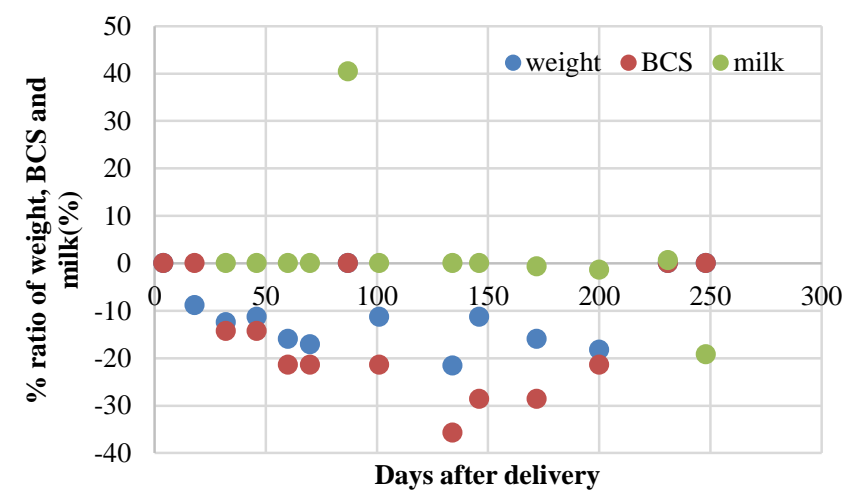

(j)

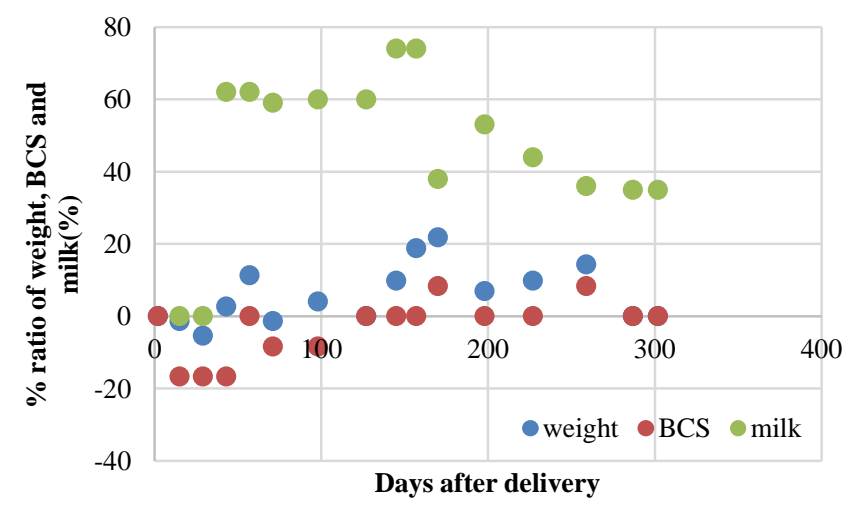

(k)

Fig. 3. Change rate of the influencing factors.

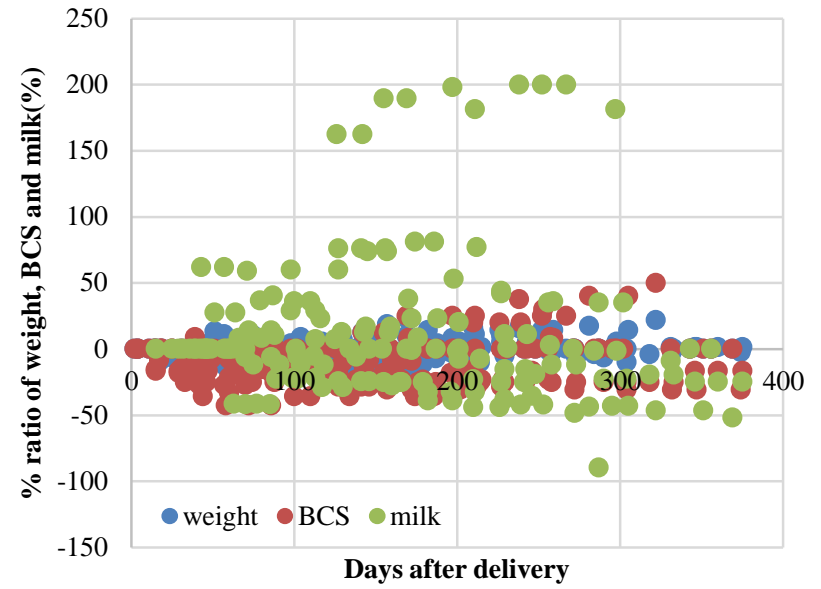

Fig. 4. Summarized results from the time series analysis.

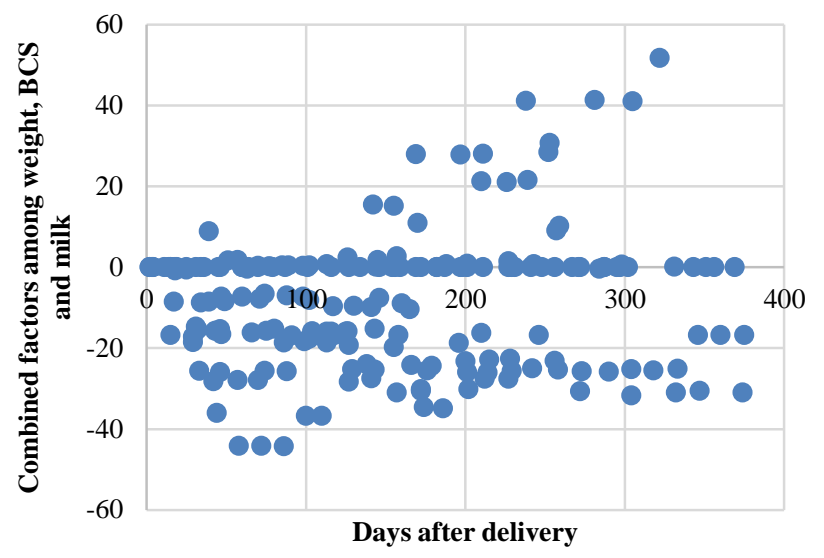

Fig. 5. Trend of the proposed index derived from the linear combination among weight, BCS and amount of milk.

Summarized results are shown in Fig. 4. Depending on influencing factors, the following linear combination of factors is proposed for the index representing recovery status of the dairy cattle after the previous delivery.

Index $=C_{0} * \mathrm{BCS}+C_{1} *$ Weight $+C_{2} *$ Amount of Milk

Fig. 5 shows the time series of the proposed index. For the proposed index can be determined with parameterization of coefficients $C_{\mathrm{i}}$ for the linear combination.

It seems a good trend which represents the recovery status of the dairy cattle as shown in Fig. 5.

Consequently, it is found that the proposed index derived from the linear combination among weight, BCS and amount of milk works well. Using this index, it is easily find the dairy cattle which need hormone treatment. Thus, the labor mean interval can be shortened.

\section{CONCLUSION}

Japanese dairy cattle productivity evaluation method based on time-series analysis with the data of visual index of Body Condition Score (BCS), Rumen Fill Score (RFS), Weight, 
Amount of Milk and Outlook is proposed. Through the experiments with 17 of dairy cattle of the candidates of 17 Japanese anestrus Holstein dairy cows, it is found that the proposed method is useful for identification of productive cattle. Therefore, the cattle which need hormone treatments can be identified. The proposed time series analysis does work for dairy cattles to find the relatively productive dairy cattles for shortened labor mean intervals.

Further study is required for finding much sensitive indicator to the readiness of pregnancy and creates a new method for identifying dairy cattle which need hormone treatment, CIDR and PG.

\section{ACKNOWLEDGMENTS}

This research work is supported by Ministry of Agriculture, Forestry and Fisheries: MAFF, Japan under the project name of "Development of technology for enhancement of livestock lifetime productivity by improving fertility through assisted reproduction". Authors would like to thank MAFF for their support as well as the students in the $4^{\text {th }}$ research group of the Department of Information Science of the Faculty of Science and Engineering of Saga University for their valuable discussions and preparation of cattle data.

\section{REFERENCES}

[1] W. Kellogg, "Body Condition Scoring with dairy cattle- FAS4008", University of Arkansas, USA, Accessed on: January 2016.

[2] G.C. Lamb, C.R. Dahlen, and D.R. Brown, "Reproductive Ultrasonography for monitoring Ovarian Structure Development, Fetal Development, Embryo Survival and Twins in Beef Cows", The Professional Animal Scientist Symposium, No. 19, 2003, pp. 135-143.

[3] J.D. Ferguson, D.T. Galligan, and N. Thousen, "Principal Descriptor of Body Condition Score in Holstein Cows", Journal of Dairy Science, No.77, 1994, pp.2695-2703.

[4] P. D. Burns, "The Dairy Cow Heat Cycle", Colorado State University, Accessed December, 2015.
[5] T.A.Zacarias, S.B. Sena-Natto, A.S. Mendonca, M.M. Franco, and R.A. Figueiredo, "Ovarian Follicular Dynamics in 2 to 3 months old Nelore Calves (Bos Taurus indices)", Journal of Animal Reproduction, Vol. 12, No.2, June,2015, pp.305-311.

[6] G. A. Perry, O. L. Swanson, E. L. Larimore, B. L. Perry, G. D. Djira, and R. A. Cushman, "Relationship of follicle size and concentrations of estradiol among cows exhibiting or not exhibiting estrus during a fixedtime AI protocol", Journal of Domestic Animal Endocrinology, 48(2014), pp.15-20.

[7] Iqbal Ahmed, Kenji Endo, Osamu Fukuda, Kohei Arai,Hiroshi Okumura Kenichi Yamashita, Japanese Dairy Cattle Productivity Analysis using Bayesian Network Model (BNM), International Journal of Advanced Computer Science and Applications, 7, 11, 31-37, 2016.

[8] Report of National Livestock Breeding Center, Japan. Website: http://www.nlbc.go.jp/en/, Accessed January, 2016.

[9] Kohei Arai, Narumi Suzaki, Iqbal Ahmed, Osamu Fukuda, Hiroshi Okumura,Kenji Endo, Kenichi Yamashita, Method for Productive Cattle Finding with Estrus Cycle Estimated with BCS and Parity Number and Hormone Treatments based on a Regressive Analysis, IJACSA, 8, 9, 191-196, 2017

\section{AUTHOR's PROFILE}

Kohei Arai, He received BS, MS and PhD degrees in 1972, 1974 and 1982, respectively. He was with The Institute for Industrial Science and Technology of the University of Tokyo from April 1974 to December 1978 also was with National Space Development Agency of Japan from January, 1979 to March, 1990. During from 1985 to 1987, he was with Canada Centre for Remote Sensing as a Post Doctoral Fellow of National Science and Engineering Research Council of Canada. He moved to Saga University as a Professor in Department of Information Science on April 1990. He was a councilor for the Aeronautics and Space related to the Technology Committee of the Ministry of Science and Technology during from 1998 to 2000. He was a councilor of Saga University for 2002 and 2003. He also was an executive councilor for the Remote Sensing Society of Japan for 2003 to 2005 . He is an Adjunct Professor of University of Arizona, USA since 1998. He also is Vice Chairman of the Science Commission "A" of ICSU/COSPAR since 2008 then he is now award committee member of ICSU/COSPAR. He wrote 37 books and published 570 journal papers. He received 30 of awards including ICSU/COSPAR Vikram Sarabhai Medal in 2016, and Science award of Ministry of Mister of Education of Japan in 2015. He is now Editor-in-Chief of IJACSA and IJISA. http://teagis.ip.is.saga-u.ac.jp/index.ht 